\title{
CFD Simulation Study on the Performance of a Modified Ram Air Turbine (RAT) for Power Generation in Aircrafts
}

\author{
Magedi Moh M. Saad ${ }^{1}$, Sofian Mohd ${ }^{2, *}$, Mohd Fadhli Zulkafli ${ }^{2}$, Nor Afzanizam Samiran ${ }^{3} \mathbb{D}$ \\ and Djamal Hissein Didane ${ }^{4}$ D
}

1 Department of Aeronautical Engineering, Engineering Academy Tajoura, Tripoli 13275, Libya; magedi983@yahoo.com

2 Department of Aeronautical Engineering, Universiti Tun Hussein Onn Malaysia, Parit Raja 86400, Malaysia; fadhli@uthm.edu.my

3 Department of Mechanical Engineering Technology, Universiti Tun Hussein Onn Malaysia, Pagoh Higher Education Hub, Pagoh, Muar 84600, Malaysia; afzanizam@uthm.edu.my

4 Center for Energy and Industrial Environment Studies, Universiti Tun Hussein Onn Malaysia, Parit Raja 86400, Malaysia; djamal@uthm.edu.my

* Correspondence: sofian@uthm.edu.my; Tel.: +60-19-752-248

Citation: Saad, M.M.M.; Mohd, S.; Zulkafli, M.F.; Samiran, N.A.; Didane, D.H. CFD Simulation Study on the Performance of a Modified Ram Air Turbine (RAT) for Power Generation in Aircrafts. Fluids 2021, 6, 391. https://doi.org/10.3390/fluids6110391

Academic Editor: Ioannis

K. Chatjigeorgiou

Received: 9 September 2021

Accepted: 19 October 2021

Published: 1 November 2021

Publisher's Note: MDPI stays neutral with regard to jurisdictional claims in published maps and institutional affiliations.

Copyright: (c) 2021 by the authors. Licensee MDPI, Basel, Switzerland. This article is an open access article distributed under the terms and conditions of the Creative Commons Attribution (CC BY) license (https:/ / creativecommons.org/licenses/by/ $4.0 /)$.

\begin{abstract}
The present paper aims to study the possibility of dispensing an auxiliary power unit (APU) in an aircraft powered by fossil fuels to reduce air pollution. It particularly seeks to evaluate the amount of power generated by the ram air turbine (RAT) using the novel counter-rotating technique while characterizing its optimum axial distance. The ram air turbine (RAT), which is already equipped in aircrafts, was enhanced to generate the amount of energy produced by the APU. The approach was implemented by a CRRAT system. Six airfoil profiles were tested based on 2D models and the best airfoil was chosen for implantation on the RAT and CRRAT systems. The performance of the conventional single-rotor RAT and CRRAT were analyzed using FLUENT software based on 3D models. The adopted numerical scheme was the Navier-Stokes equation with $\mathrm{k}-\omega \mathrm{SST}$ turbulence modeling. The dynamic mesh and user-defined function (UDF) were used to revolve the rotor turbine via wind. The results indicated that the FX63-137 airfoil profile showed a higher performance in terms of the lift-to-drag ratio compared to the other airfoils. The optimum axial distance between the two rotors was $0.087 \mathrm{~m}$ of the rotor diameter and the efficiency of the new CRRAT increased to almost $45 \%$ compared to the single-rotor RAT.
\end{abstract}

Keywords: ram air turbine; counter-rotating ram air turbine; CFD fluent; airfoil performance

\section{Introduction}

Fuel combustion in transportation typically produces the emission of pollutants that cause damage to human health, agriculture, and sensitive ecosystems, as well as contribute to global climate change [1]. The ram air turbine (RAT) is identified as one of the potential technologies that are applicable to reduce the dependency on conventional fossil fuel combustion systems in aircrafts. RAT is a small wind turbine that converts wind energy into electrical energy to operate devices in aircrafts. The conventional system for energy generation in aircrafts, such as the auxiliary power unit (APU) which consumes nonrenewable fossil fuels, is detrimental to the environment [2].

The auxiliary power unit (APU) is a small gas turbine engine that makes the aircraft independent of ground power supplies. APU works to support the electrical and air conditioning systems during the main engine shut down, provides pneumatic power for the main engine during start-up, enhances the electrical margin, and mitigates the working engine's load during flight. The APU unit somehow contributes to several drawbacks of the aircraft system. It is exposed to immediate thermal damage when the performance of the stator component is gradually degraded. The stator in APU is a component that accelerates 
APU rotational speed to provide sufficient compressed air for self-sustaining operation. Thus, the damage of APU results in unnecessary economic losses and operational safety issues. APU is also identified as an undesirable device in serving power [3]. It was found that eliminating an APU offers a reduction in the weight of an aircraft body, resulting in increased performance and fuel saving [4]. Hence, aircrafts without APU provide economic and ecological benefits.

The RAT concept is one of the potential alternative devices that are applicable to replace the APU system. RAT can be used to generate wind energy during landing operation for the super-charging process of the high-capacity battery. The stored energy is available for future take-off and landing operations. However, the existing conventional RAT in aircrafts produces energy for emergency events only, such as engines failure. Hence, a large backup of power is required for more extended endurance flights, which helps in safe landing [5]. RATs are idle under normal circumstances and used during emergency phases, whereas other power systems, such as APUs, are used to power certain amenities in the aircraft, such as air conditioners and lights before the engine is started [6]. RATs are not sufficiently durable for flights at high altitudes and energy by RATs is only sufficient to maintain aircraft operations during emergency phases until the nearest runway is reached for landing [7]. Thus, modification is required to increase the efficiency of RAT in harvesting energy. It was observed that RAT needs to produce energy at 115-120 kVA to be comparable with the APU ability [8].

The counter-rotating ram air turbine (CRRAT) is one of the potential wind turbine systems that can increase the performance of the conventional single-rotating turbine RAT. The studies that applied the counter-rotating implemented multiple design schemes to meet the required performance. This technology involves the employment of multiple-blade air turbines to maximize the overall efficiency. There are many key players influencing the turbine performances, such as the axial distance and blade design (blade's profile).

Kumar et al. [9] conducted CFD and an experimental analysis for a single-rotor and counter-rotating wind turbine rotor with 2D and 3D models of the Airfoil (NACA 0012 and NACA 4415) using a multi-reference frame. The results suggested that the output power was increased as the axial distance between the rotors was increased. Xuesong et al. [10] also conducted experimental work of wind tunnel testing to investigate the influence of blade pitch angle and axial distance on the performance of the counter-rotating-type horizontal-axis tidal turbine (HATT). The results showed that the increase in blade pitch angles and axial distance increased the performance of a counter-rotating turbine. The counter-rotating rotors exhibited a higher $C_{p}$ value and tip-speed ratio range as compared to a single rotor system. Lee et al. [11] compared the performance of a counter-rotating system with a two and four-bladed single-rotor system using the vortex method. The results showed that the efficiency of a counter-rotating wind turbine (CRWT) was 30\% higher than a single rotor with a half solidity, but $5 \%$ less than a single rotor with equal solidity.

Kumar et al. [9] investigated the characteristics of the upwind primary rotor and the downwind secondary rotor of the contra rotor wind turbine to increase the aerodynamic performance by using computational fluid dynamics (CFD). Three-bladed single and threebladed contra-rotating rotors were compared by using CFD. The thrust computed produced a linearly steep curve 35\% higher for CRWT than SRWT for the same wind speed at $10 \mathrm{~m} / \mathrm{s}$. Kumar et al. [12] conducted a simulation and experimental study using the commercial software of Fluent 6.2 and wind tunnel testing, respectively, to analyze the performance of CRWT with different diameters as well as power and torque characteristics. The result showed that there is a power increment for CRWT as compared to the single-rotor wind turbine (SRWT).

Lee et al. [13] used a two-bladed rotor of CRWT and the free wake vortex lattice method in this approach to investigate and analyze the interaction between the front and rare rotors, which the inflow velocity assumption was applied to in this study. The maximum power coefficient of the counter-rotating rotor was increased by $12 \%$ from that of the single rotor. It was also found that the distance between the rotors controlled the 
fluctuation of the power coefficients. Pereira et al. [14] studied the performance of micro air turbines. The performance of different turbines was compared based on fluid flow behaviors. The study outcomes stated that a more effective air turbine with counter-rotating could be achieved by increasing the gap (horizontal distance) and using five blades with the right curvature. Jung et al. [15] reported that the double rotor turbine produced a $65 \%$ of power output whereas the single rotor is $43 \%$ with the same wind speed and rotor diameter. This approach was conducted by changing the separation distance of those rotors to reach the optimum power. The optimum distance was found equal to $50 \mathrm{~mm}$ with a $\mathrm{C}_{\mathrm{p}}$ value equal to 0.457 . Similarly, more recent studies of a vertical axis CRWT performed by Didane et al. [16-19] indicated that decreasing the axial distance leads to an increase in the overall performance of the two counter-rotating rotors.

From all the previous research, it is envisioned that CRWT can be employed to improve the RAT design in generating energy. It is also observed that the existing designs of RAT systems do not use the counter-rotating technique in extracting energy from the wind, although its advantages are found to be significant. Thus, this study aims to design and critically evaluate the performance of the RAT with the best airfoil blade system, while adopting the counter-rotating technique by using the CFD simulation approach. However, air-driven energy is challenging for aircraft designers. Such technology is impractical for take-off and normal flight operations, as the device is not durable at high wind speed [20]. Thus, the present study focused on the operation of RAT during the landing phase (decelerate phase) of aircrafts and enhanced the power output in the emergency phase to maintain aircraft flight until it reaches the nearest runway for landing. The energy obtained is stored in the aircraft. The drag produced by the RAT extraction is expected to be capable of recharging the batteries instead of being lost.

\section{Materials and Methods}

This study was performed based on both 2D and 3D CFD simulation methods using the commercial FLUENT ANSYS v15.0. The 2D simulations were conducted on six different airfoils in order to select the airfoil profile that showed the highest performance in terms of the lift-to-drag ratio for implementation on the CRRAT and SRRAT systems, which were designed and simulated based on 3D models afterwards.

\subsection{Governing Equations}

The Navier-Stokes equations based on the law of conservation of the physical properties of fluid flow were used as the governing equations of the simulation process. The continuity and momentum equations in their conservative form are given in Equations (1) and (2), respectively. For the purpose of solving the governing formulas, the Finite Volume Method and Moving Reference Frame (MRF) technique were used and hence modulated the flow surrounding both the single-rotor wind turbine and counter-rotating wind turbine.

$$
\begin{gathered}
\frac{D \rho}{D t}+\rho \frac{\partial U_{i}}{\partial x_{i}}=0 \\
\rho \frac{\partial U_{j}}{\partial_{t}}+\rho U_{i} \frac{\partial U_{j}}{\partial x_{i}}=-\frac{\partial P}{\partial x_{j}}-\frac{\partial \tau_{i j}}{\partial x_{i}}+\rho g_{i}
\end{gathered}
$$

where:

$$
\tau_{i j}=-\mu\left(\frac{\partial U_{j}}{\partial x_{i}}+\frac{\partial U_{i}}{\partial x_{j}}\right)+\frac{2}{3} \delta_{i j} \mu \frac{\partial U_{k}}{\partial x_{k}}
$$

The properties are as follows: local change of time, $\rho \frac{\partial U_{j}}{\partial_{t}}$;

momentum convection, $\rho U_{i} \frac{\partial U_{j}}{\partial x_{i}}$;

surface force, $-\frac{\partial P}{\partial x_{j}}$;

molecular-dependent momentum exchange, $\frac{\partial \tau_{i j}}{\partial x_{i}}$; and 
mass force, $\rho g_{i}$.

The two-equation $k-\omega$ shear stress transport (SST) turbulence equation was used as the turbulence model. Equation (4) shows the specific turbulent kinetic energy, $k$, while the specific turbulent frequency, $\omega$, is shown in Equation (5).

$$
\frac{\partial(\rho k)}{\partial t}+\frac{\partial\left(\rho U_{i} k\right)}{\partial x_{i}}=\widetilde{P}_{k}-\beta^{*} \rho k \omega+\frac{\partial}{\partial_{x_{i}}}\left[\left(\mu+\sigma_{k} \mu_{t}\right) \frac{\partial k}{\partial_{x_{i}}}\right]
$$

$$
\frac{\partial(\rho \omega)}{\partial t}+\frac{\partial\left(\rho U_{i} \omega\right)}{\partial x_{i}}=\alpha \rho S^{2}-\beta \rho k \omega^{2}+\frac{\partial}{\partial_{x_{i}}}\left[\left(\mu+\sigma_{\omega} \mu_{t}\right) \frac{\partial \omega}{\partial_{x_{i}}}\right]+2\left(1-F_{1}\right) \rho \sigma_{\omega, 2} \frac{1}{\omega} \frac{\partial k}{\partial_{x_{i}}} \frac{\partial \omega}{\partial_{x_{i}}}
$$

where $\widetilde{P}_{k}$ and $F_{1}$ are the rate of the production of turbulent kinetic energy and the blending function, respectively. Meanwhile, $\mu_{t}$ is the modified eddy viscosity, while $\sigma_{k}$ and $\sigma_{\omega}$ are the diffusion constants of the models.

\subsection{Model Geometry, Domain, and Mesh Setup of Airfoil}

In this section, six airfoils were tested, as shown in Figure 1. The types of airfoils were NACA 63415, S835, S809, FX63-137, FX76-100, and NACA 63-215 [21-26]. The details of the airfoil thickness are presented in Table 1. The optimum design of the airfoil was justified based on the maximum value of L/D. Analysis of the lift and drag forces was investigated and compared between those airfoils. Figure 2 shows the geometry and boundary conditions for the simulation of airfoils. The simulation was performed for a two-dimensional domain in which the tip effects were not considered. Reynolds number for the turbine was set at $\operatorname{Re}=4 \times 10^{6}$.
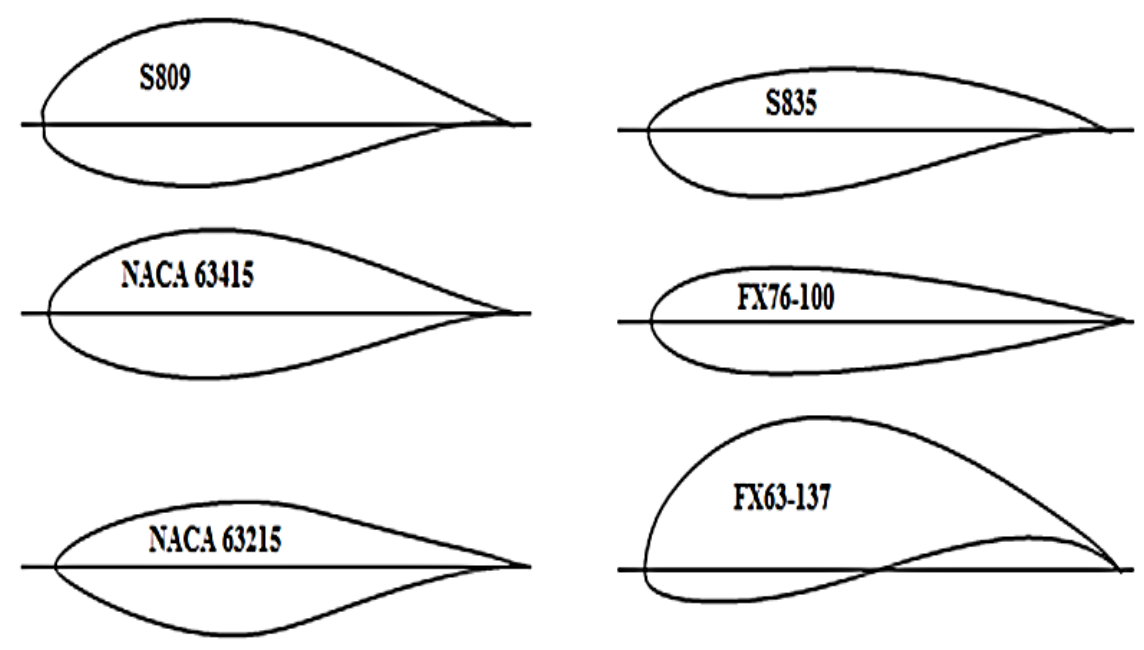

Figure 1. Airfoil geometry.

The airflow speed and pressure subjected to the airfoil were set at $70 \mathrm{~m} / \mathrm{s}$ and under atmospheric conditions, respectively. The outflow boundary condition was set at a static pressure of $1 \mathrm{~atm}$. The velocity inlet was set according to the direction of the angle of attack. Various angles of attack were examined for a freestream velocity of $\mathrm{U} \mathrm{m} / \mathrm{s}$. The formulas of specific inlet conditions used were $\mathrm{u}=\mathrm{U} \cos \alpha$ and $\mathrm{v}=\mathrm{U} \cos \alpha$. The simulation was also set as unsteady-state-type, with ideal gas as a fluid domain, and Standard k- $\omega$ SST as a turbulence model $[20,24,27,28]$. The grid used for the simulations was designed using GAMBIT and is shown in Figure 3. All grids are structured C-Type mesh [29-32] with a total of 10,723 grid points. 


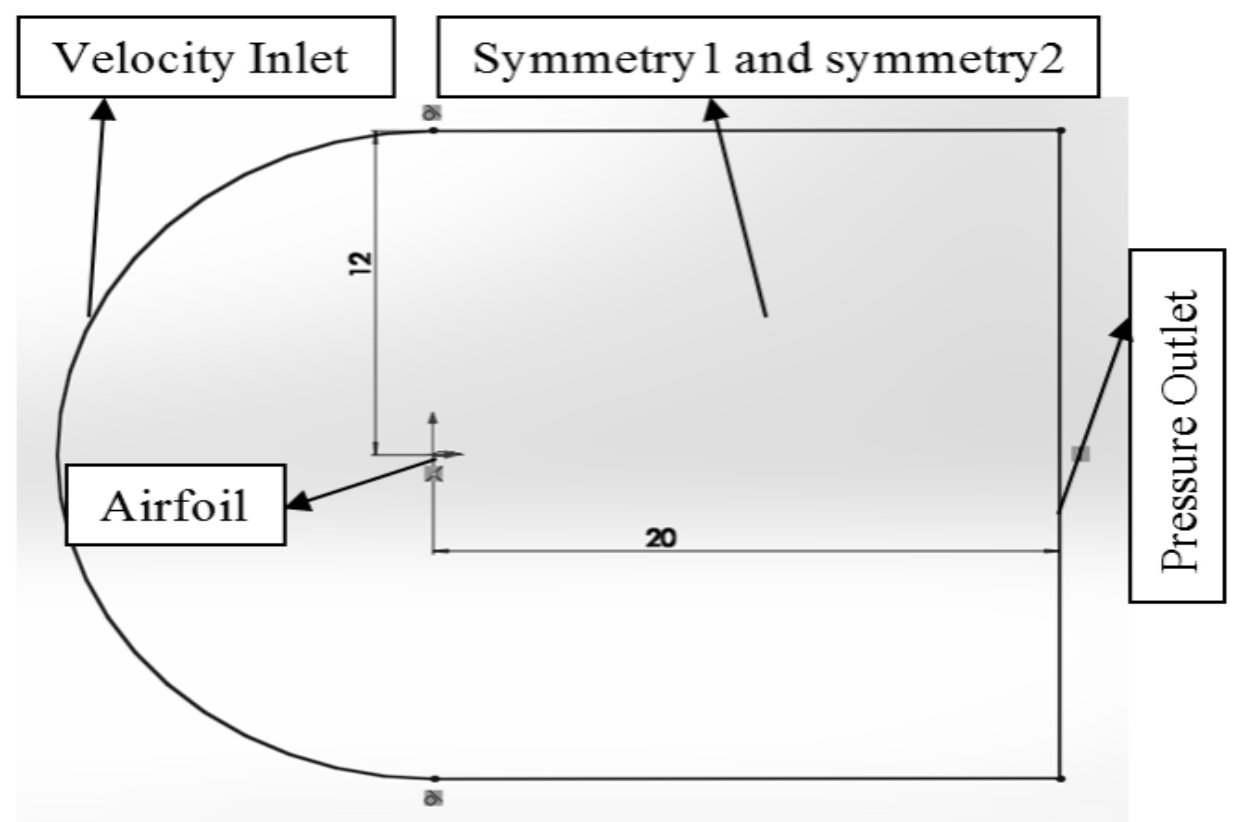

Figure 2. Boundary zone for airfoil.
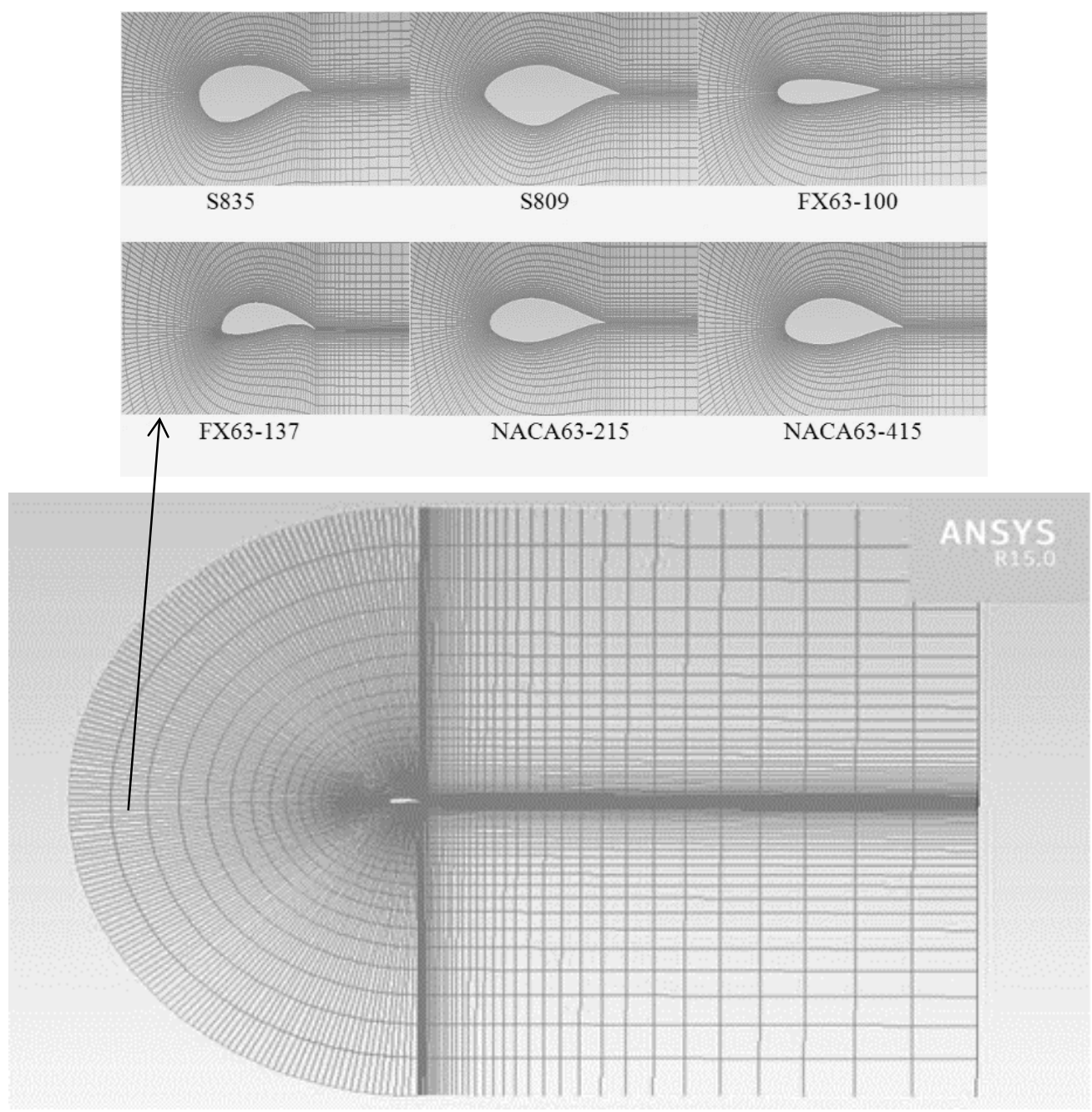

Figure 3. Mesh around airfoil. 
Table 1. Thickness and maximum thickness for airfoils.

\begin{tabular}{ccccccc}
\hline & NACA 63-415 & FX76-100 & S835 & S809 & FX63-137 & NACA 63-215 \\
\hline Thickness & $15 \%$ & $10.07 \%$ & $21.05 \%$ & $21 \%$ & $13.70 \%$ & $10.07 \%$ \\
\hline $\begin{array}{c}\text { Max. thickness from } \\
\text { leading edge }\end{array}$ & $34.90 \%$ & $27.30 \%$ & $30.70 \%$ & $36.40 \%$ & $29.20 \%$ & $27.30 \%$ \\
\hline
\end{tabular}

\subsection{Domain, Boundary Conditions, and Mesh of the CRRAT and SRRAT System}

Figure 4 shows the geometry and boundary conditions for the simulation of the CRRAT and SRRAT systems. The distance of the rotor from the inlet and outlet were estimated at 1 and $2 \mathrm{~L} / \mathrm{D}$ of the cylinder domain boundary, respectively [29-34]. Pressure far-fields were set as the boundary condition at the lateral boundaries. The inlet, outlet, and turbine domain were set as the inlet velocity at $70 \mathrm{~m} / \mathrm{s}$, the pressure outlet at $101,325 \mathrm{~Pa}$, and the wall (non-slip wall), respectively. In this case, three-dimensional meshes were implemented. The grid quality was dependent on the degree of skewness and orthogonal quality [33-36]. Thus, each critical edge position, as in Figure $4 b, c$, required an appropriate mesh size set-up. High-quality mesh exhibits a skewness value of closer to zero. In this case, the maximum skewness was recorded at less than 0.85 . The total number of mesh elements for SRRAT and CRRAT were 2,574,225 and 13,414,878, respectively, and the mesh generated for both models is depicted in Figure 4d,e.

\subsection{Solver Setup}

The rotation of the rotor was rendered by using dynamic mesh and the User Defined Function (UDF). The physical properties, such as mass properties and the rotational axis of the rotor, were defined in the UDF medium written in C-language. The size of the time step was set at $1 \times 10^{-5} \mathrm{~s}$. The solver, space, time, and velocity conditions were set as pressure-based, 3D, transient, and absolute conditions, respectively. The fluid properties for the boundary condition were set for an air medium with a density and dynamic viscosity of $1.125\left(\mathrm{~kg} / \mathrm{m}^{3}\right)$ and $1.789 \times 10^{-5}(\mathrm{~kg} / \mathrm{m} \cdot \mathrm{s})$, respectively. The turbulence specification method used the intensity and hydraulic diameter scheme. The adopted numerical scheme was the Navier-Stokes equation with k- $\omega$ SST turbulence-modeling.

\subsection{Model Validation}

The validation of the present work is presented in this section. The results of the lift and drag coefficient of the FX63-137 airfoil for 106 Reynolds numbers that were obtained using FLUENT were compared with the previous experimental results of the wind tunnel test [23], as shown in Figure 5. The FLUENT results showed a good agreement with the experimental results for the lift and drag coefficient. Results of the numerical study proved that the optimized airfoil FX63-137 demonstrated high aerodynamic performance in high wind speeds, which was later adopted for the analysis of both CRRAT and SRRAT. 

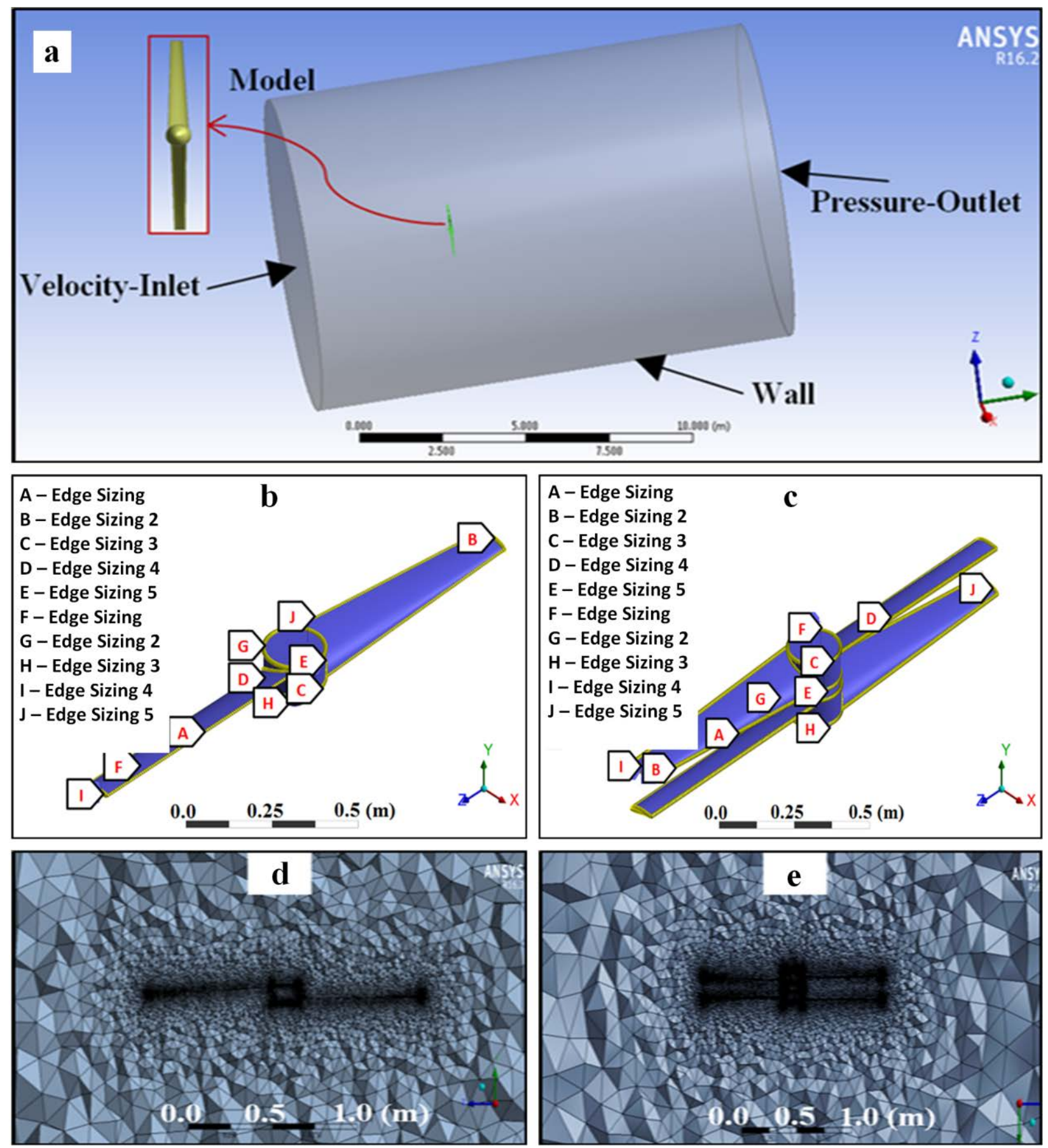

Figure 4. (a) Boundary condition; geometry with mesh sizing at edge location for (b) SRRAT and (c) CRRAT; and structure of saturated, fine, and coarse mesh for (d) SSRAT and (e) CRRAT. 


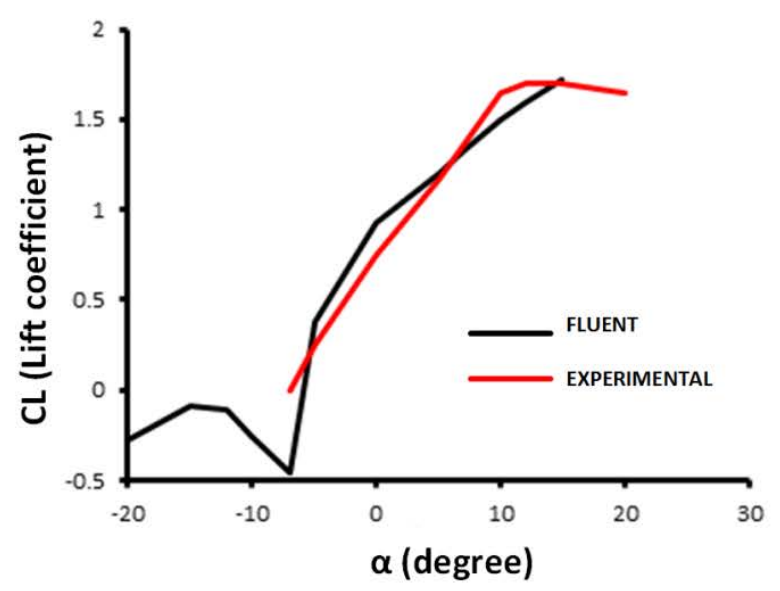

(a)

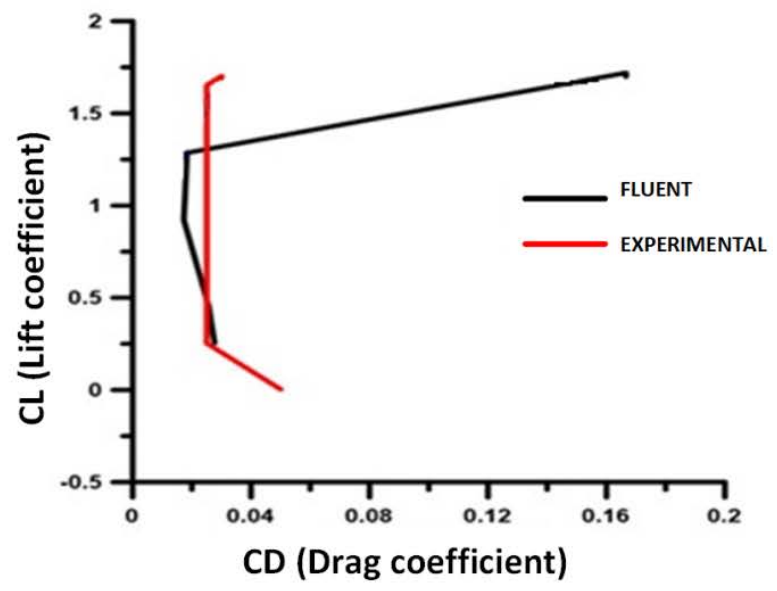

(b)

Figure 5. The validation results for FX63-137 of FLUENT and the experimental work presented in [34] (a) lift coefficient vs. the angle of attack $\alpha^{\circ}(\mathbf{b})$ lift coefficient, wherein $C_{l}$ vs. the drag coefficient $C_{d}$.

\section{Results and Discussion}

The performance analysis for the CRRAT system study is comprised of two parts. The first part embodies the aerodynamic performance analysis on the different shapes of airfoils at different angles of attack. The optimum design and shape of the airfoil in the first part is then implemented in the second part. The second part involves a comparative study between the performances of a CRRAT system with two-bladed co-rotating and counter-rotating rotors and a conventional SRRAT system. The potential of the CRRAT system to be implemented in aircrafts was also evaluated in this section.

\subsection{Part 1: Airfoil Analysis}

\subsubsection{Pressure and Velocity Contour of Airfoil}

The normal pressure drag depends upon the viscosity of the air and is related to flow separation. Figure 6 shows the pressure distribution of six airfoils at different angles of attacks, specifically AOA $(\alpha=0, \alpha=7,12$, and $\alpha=-7)$. At low AOA, the high pressures near the leading edge produced a component of force in the rearward (i.e., drag) direction, while the low pressures above the airfoil body (maximum thickness point) tended to pull the wing section forward, giving a thrust effect. Figure 6 also shows that the pressure was decreased at the leading-edge region as the AOA of the wing section increased, hence increasing the suction effect. This caused the pressure at the lower pressure region to increase when the air moved further downstream. The pressure gradient became more significant as the angle of attack increased.

Figure 7 shows contour plots of the velocity distributions at AOA of $\alpha=0^{\circ}, \alpha=7^{\circ}$ $\alpha=12^{\circ}$, and $\alpha=-7^{\circ}$ for Reynolds numbers of $4 \times 10^{6}$, corresponding to an airspeed of $\mathrm{U}=70 \mathrm{~m} / \mathrm{s}$. The essential features of the flow over an airfoil were visible, indicating that at least qualitatively accurate results emerge, depicting a stagnation point at the leading edge and trailing edge of the airfoil, and at the wake behind the airfoil where fluids must accelerate to match the free stream. By comparing the detailed flow fields of the airfoils, the effect of separation on the airfoils' boundary layers was analyzed. There is a subtle flow separation in the trailing edge. Beginning with angle $\alpha=12^{\circ}$, the separation became larger and significantly influenced the wing characteristics, increasing the drag force and decreasing the lift force. 


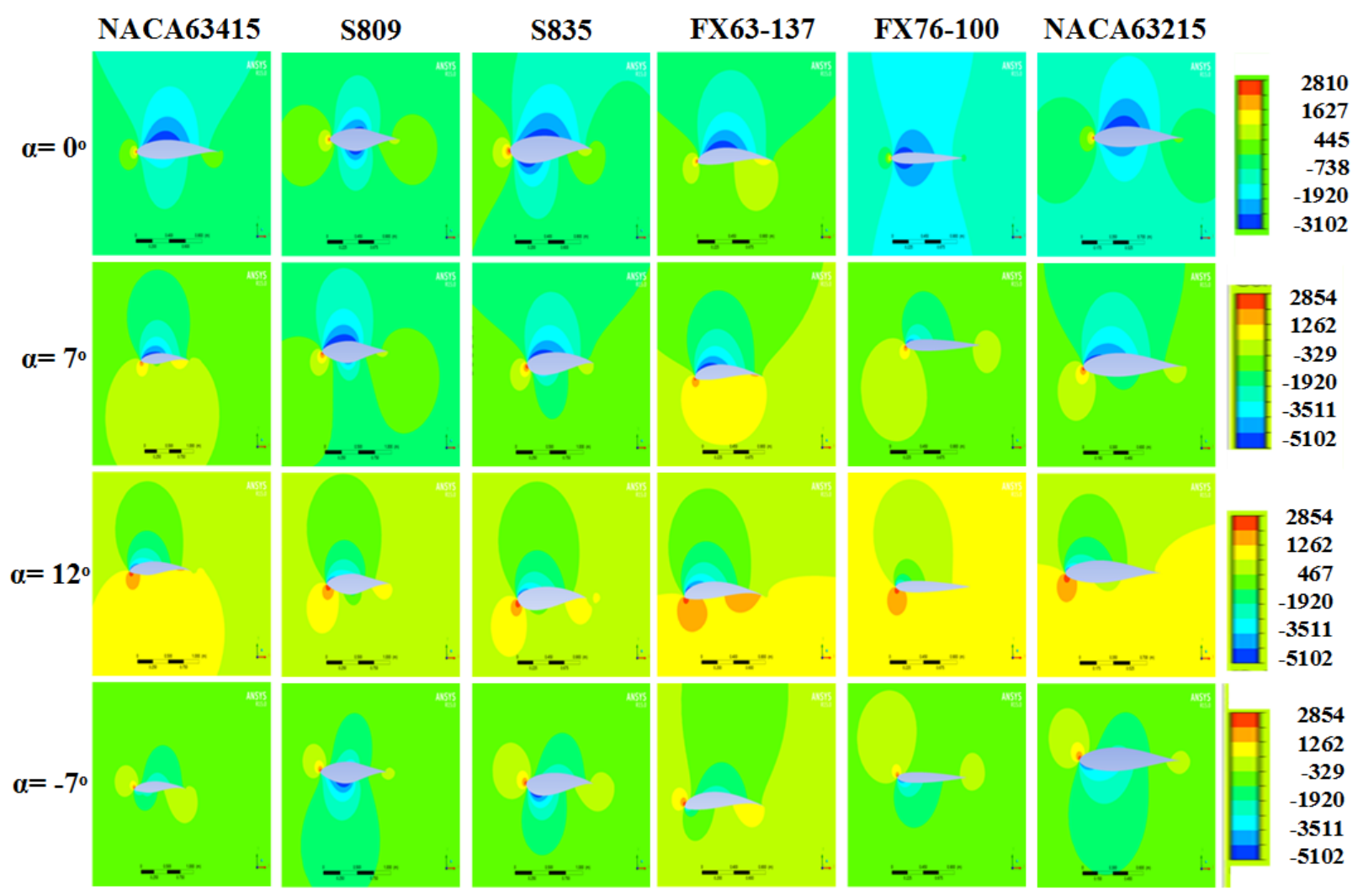

Figure 6. Pressure contour around airfoils.

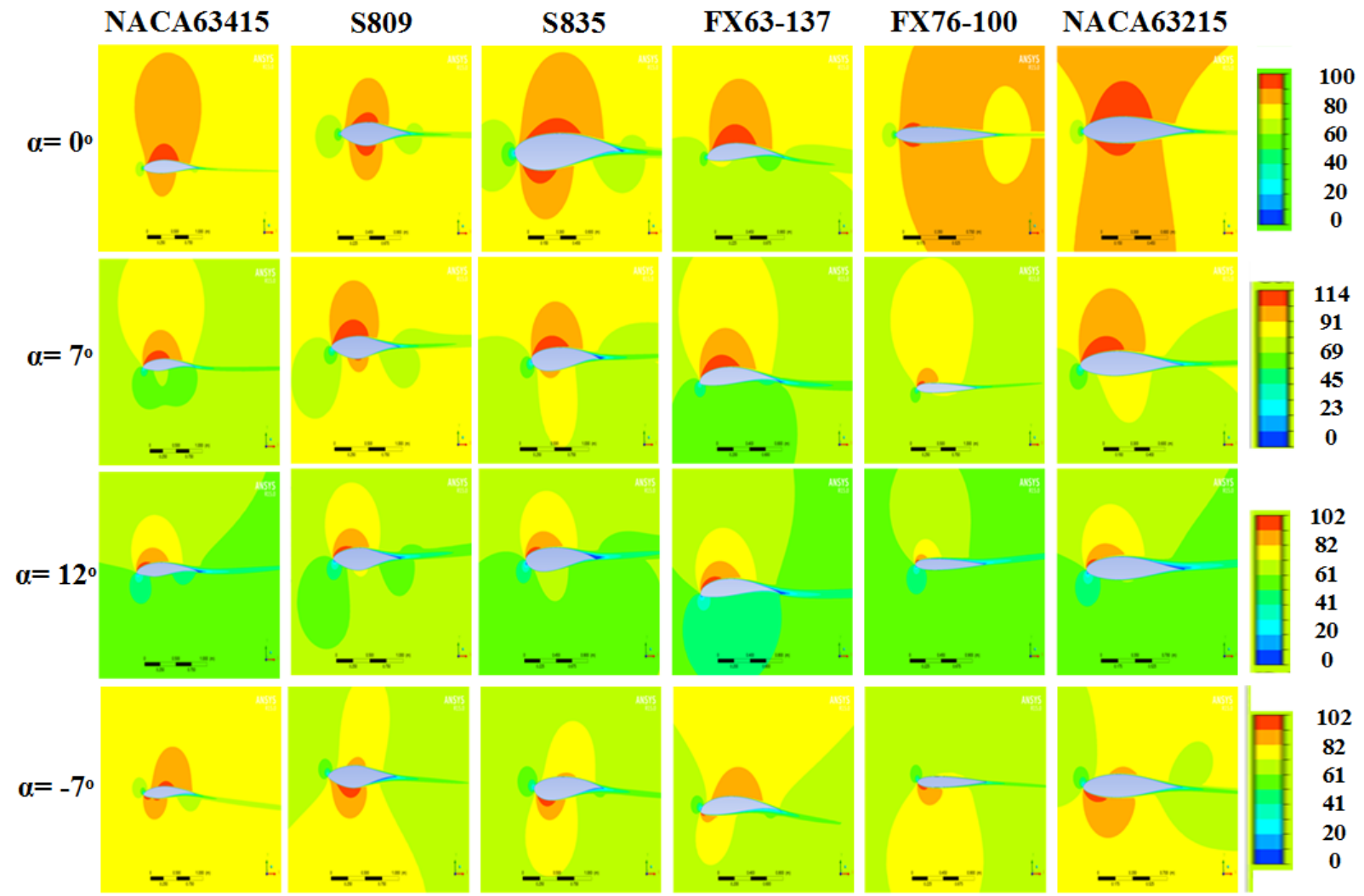

Figure 7. Velocity contour around airfoils. 
It is observable that the pressure on the upper surface is negative, while the velocity on the upper surface is higher than the reference velocity. Whenever there are high-velocity vectors, we have low pressures and vice versa.

\subsubsection{Drag Coefficient, Lift Coefficient, and Angle of Attack}

This section aims to select the optimum airfoil by the maximum $C_{l} / C_{d}$ ratio of the six airfoils. The FLUENT results shown in Figure 8 indicate that the maximum $C_{l} / C_{d}$ for FX63137 was around 110.725 and occurred at the angle of attack of $5^{\circ}$, which is the optimum angle of attack, $\alpha$ FX63-137 also exhibited the maximum $C_{l}$ of 1.7213, which occurred at the angle of $15^{\circ}$, as shown in Figure 8. In addition, the lift coefficient of FX63-137 at $0^{\circ}$ angle of attack was higher (0.923) as compared to the other airfoils, which ranged between 0.18 and 0.35 , as shown in Figure 9. The simulation results hence conclude that the airfoil type of FX63-137 was the optimum design in terms of aerodynamic performance in the high Reynolds number flow region. Results of the numerical study proved that the optimized airfoil FX63-137 demonstrated high aerodynamic performance at high wind speeds.
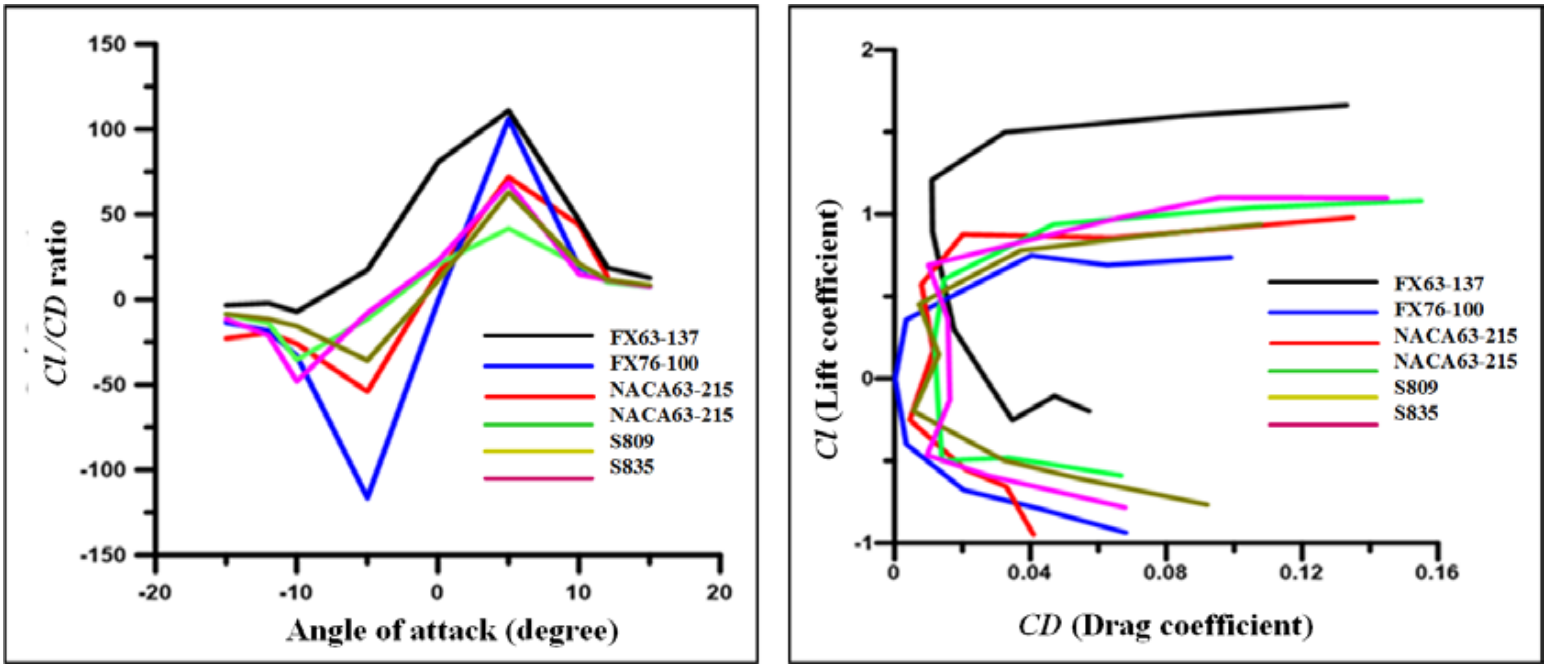

Figure 8. The $C_{l} / C_{d}$ coefficient as a function of $\alpha^{\circ}$ and the lift coefficient as a function of the drag coefficient.

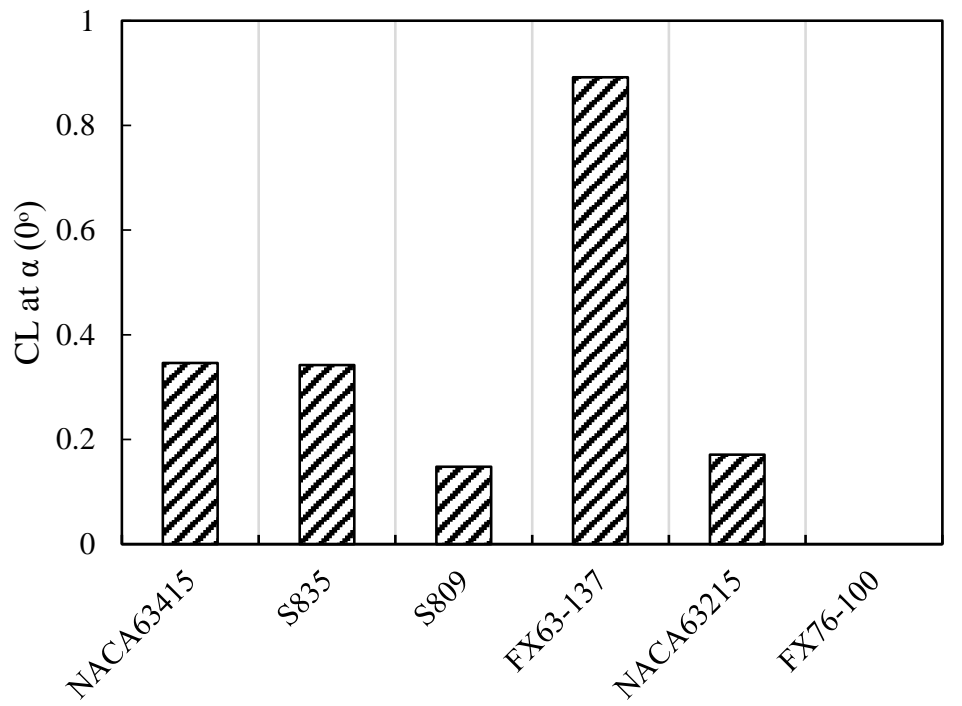

Airfoil type

Figure 9. Lift coefficient at $0^{\circ}$ angle of attack. 


\subsection{Part 2: CRRAT and SRRAT Analysis}

\subsubsection{Effect of Rotor Axial Distance in the CRRAT System}

The effect of the axial distance between the front and rear rotor in the CRRAT system was thoroughly studied in this section. The numerical simulation was performed for various setups of axial distances, including $10 \mathrm{~cm}, 14 \mathrm{~cm}$, and $17 \mathrm{~cm}$. The results showed that the rotor produces drag coefficients of $0.55,0.58$, and 0.57 for the front rotor at the axial distances of $10 \mathrm{~cm}, 14 \mathrm{~cm}$ and $17 \mathrm{~cm}$, respectively. For the rear rotor, the drag coefficients produced were $0.51,0.56$, and 0.55 for the axial distances of $10 \mathrm{~cm}, 14 \mathrm{~cm}$, and $17 \mathrm{~cm}$, respectively. The analysis results also depicted that the counter-rotating system achieved higher efficiencies of $13.72 \%$ and $9.04 \%$ for the front and rear rotor, respectively, at an axial distance of $14 \mathrm{~cm}$, as compared to the axial distance of $10 \mathrm{~cm}$ and $17 \mathrm{~cm}$, as shown in Figure 10.

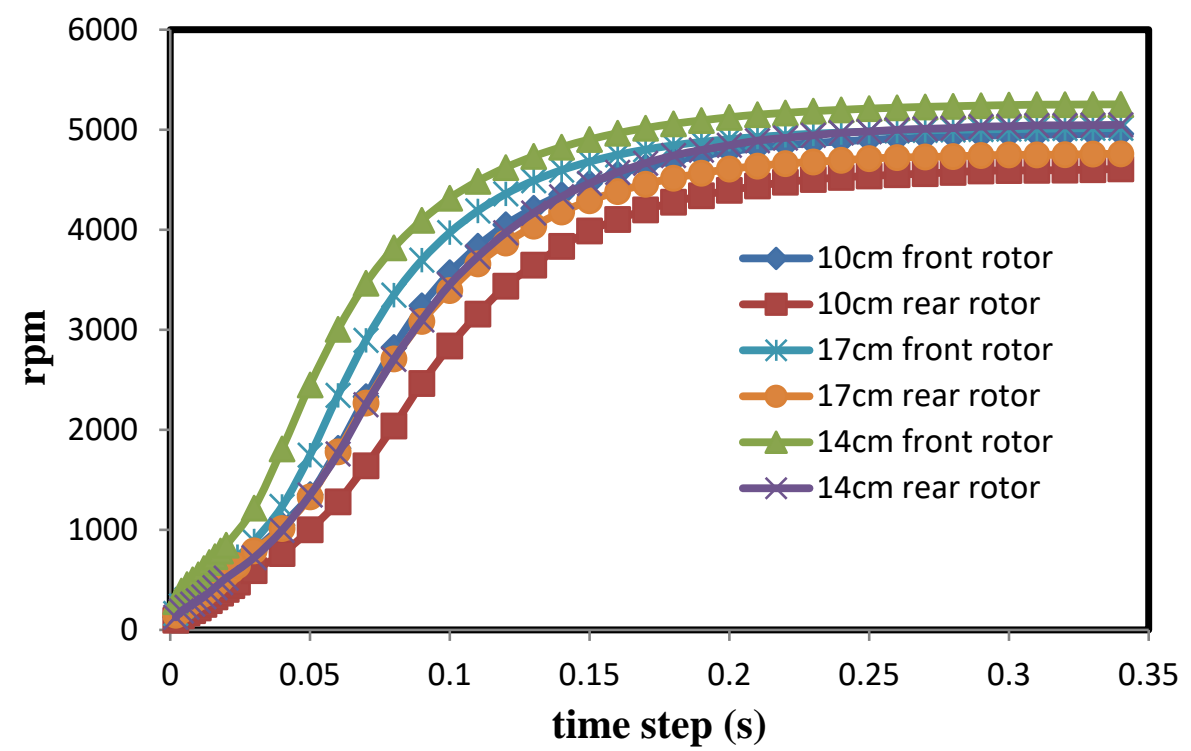

Figure 10. Relationships between rpm and time step.

Figure 10 also illustrates that the rotational speeds for all cases were reaching steady states at an average time-step of $0.34 \mathrm{~s}$. The speed of the front rotor at axial distances of 10 , 14, and $17 \mathrm{~cm}$ were 4960.189, 5246.002, and $5016.204 \mathrm{rpm}$, respectively. The speed for the rear rotor at axial distances of 10,14, and $17 \mathrm{~cm}$ were $4609.219,5034.083$, and $4759.33 \mathrm{rpm}$, respectively. At an axial distance of $10 \mathrm{~cm}$, the vortices produced from the front rotor blades will affect the rear rotor, as illustrated in Figure 11a. At an axial distance of $17 \mathrm{~cm}$, the vortices produced from the distance between the rotor hubs acted on the rear rotor performance, whereas at an axial distance of $14 \mathrm{~cm}$, no significant effects of the distance between the rotor hubs and the short distance between the rotor blades were observed in Figure $11 b, c$. 


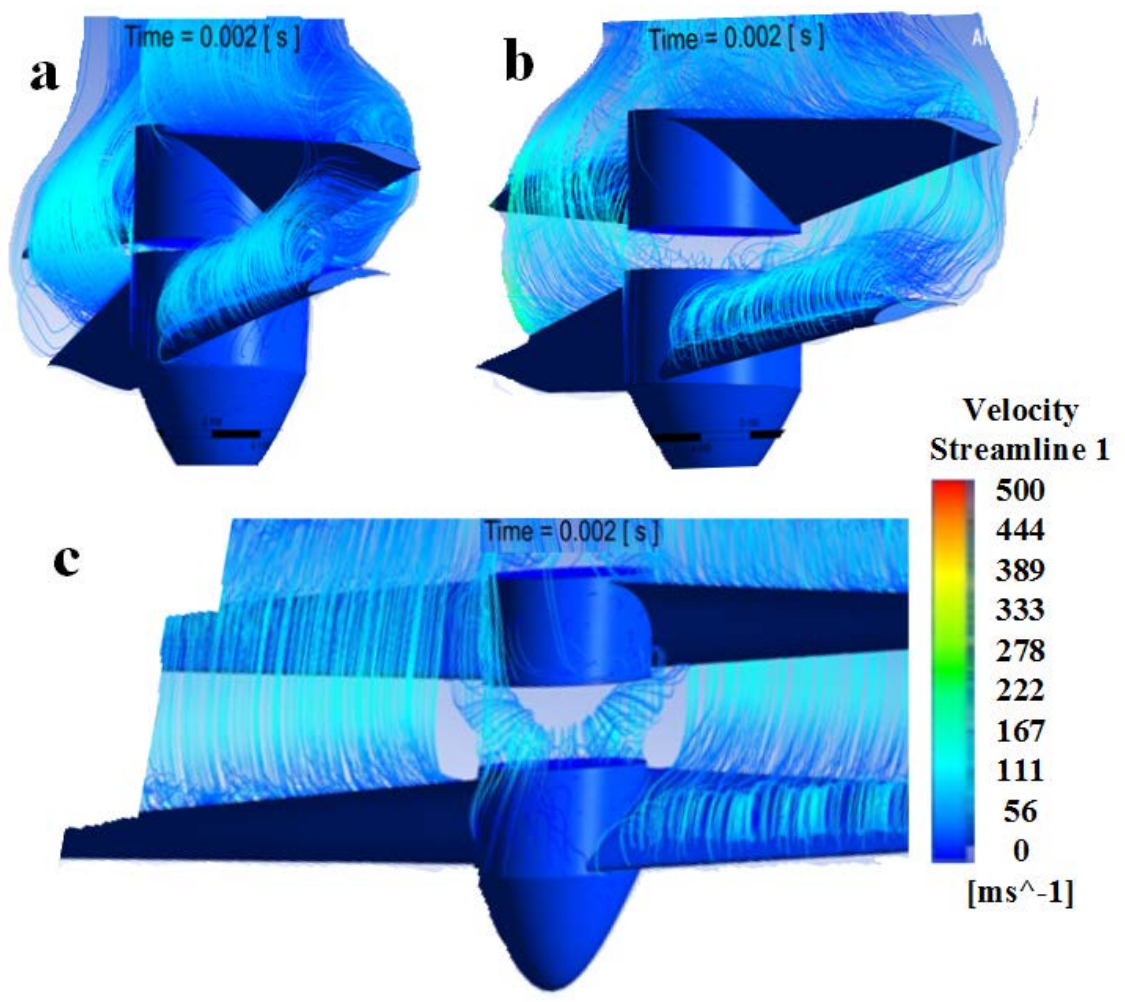

Figure 11. Velocity streamline at an axial distance of (a) $10 \mathrm{~cm},(\mathbf{b}) 14 \mathrm{~cm}$, and (c) $17 \mathrm{~cm}$.

\subsubsection{Comparative Performance between CRRAT and SRRAT}

The comparison between SRRAT and CRRAT at an optimum axial distance of $14 \mathrm{~cm}$ was simulated at the same boundary conditions. As shown in Figure 12, the SRRAT and CRRAT exhibited steady states at the time-step of $0.3 \mathrm{~s}$. At the time-step of $0 \mathrm{~s}$ to $0.1 \mathrm{~s}$, the speed of the front rotor was higher and no significant difference in the performance of the rear rotor was observed as compared to the single rotor. The results are consistent with the previous experimental study [37]. For the time-step above, specifically $0.1 \mathrm{~s}$ (high rpm), no significant difference of speed for the front rotor was observed as compared to the single rotor. The rear rotor kept increasing as the time-step increased.

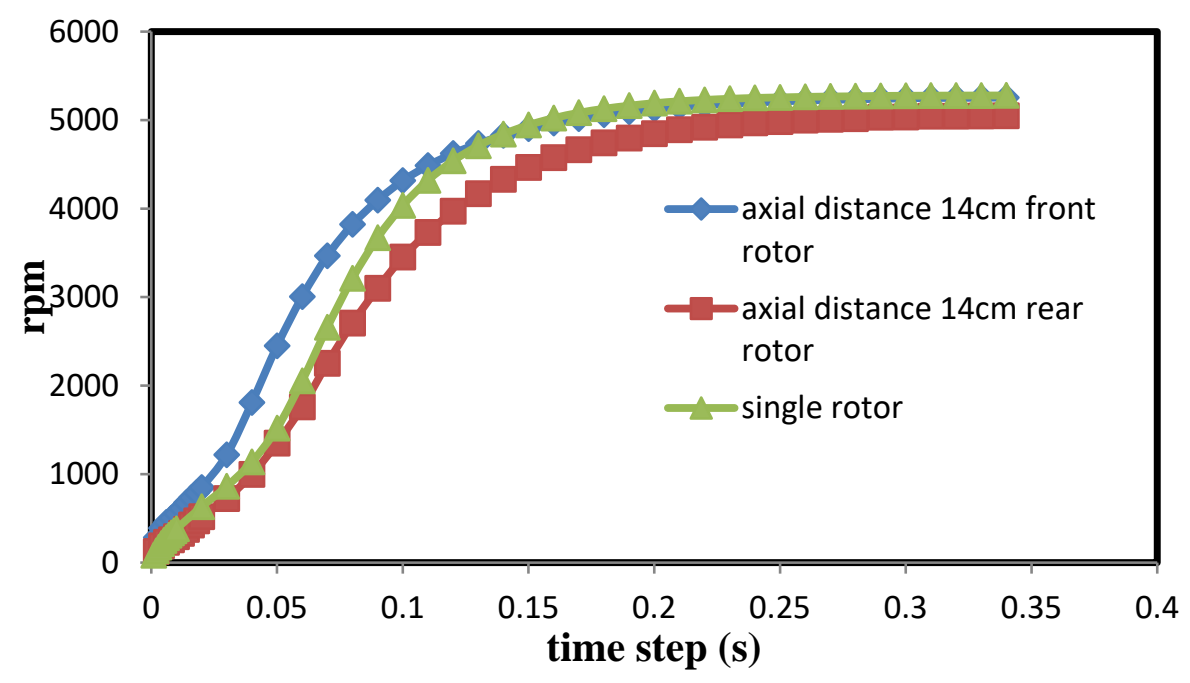

Figure 12. Comparison between SRRAT and CRRAT at an axial distance of $14 \mathrm{~cm}$. 
The speed of SRRAT was recorded at $5278.428 \mathrm{rpm}$, whereas the front and rear rotors were $5246.002 \mathrm{rpm}$ and $5034.083 \mathrm{rpm}$, respectively, as the speed was in a steady-state condition. At time $0 \mathrm{~s}$, the air velocity started to increase between the front and rear rotor due to the blade shape, thus increasing the rotational speed of the front rotor. At low rotational speed, the airflow at the rear rotor was reflected back to the front rotor, which caused the rotational speed to increase. Figure 13a,b shows the flow stream region of the CRRAT at 0.004 and $0.006 \mathrm{~s}$, whereas Figure $13 \mathrm{c}$ shows the flow stream region of the SRRAT at $0.004 \mathrm{~s}$. It could also be observed that the maximum velocity occurs at the tip of both the single-rotor (Figure 13c) and dual-rotor CRRAT (Figure 13a,b). Moreover, the existence of the second rotor (Figure 13a,b) has created more turbulence due to the shear stem from the velocity difference and the velocity has both increased and changed direction. Thus, the rotor at the rear, which rotates in the opposite direction to the rotor in front, took advantage of this phenomenon and received increased velocities. However, the effect of vortex shading was more profound for the single-rotor RAT compared to the dual-rotor RAT design.

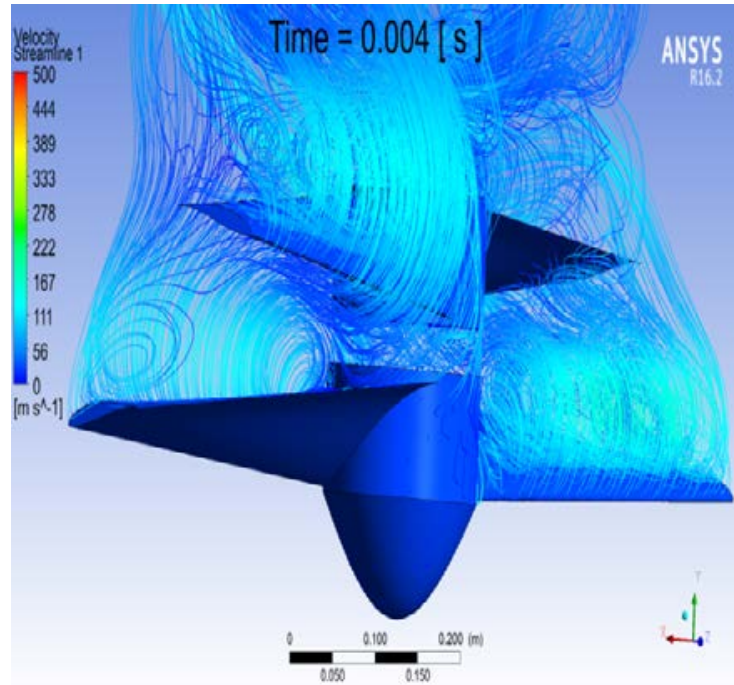

(a)

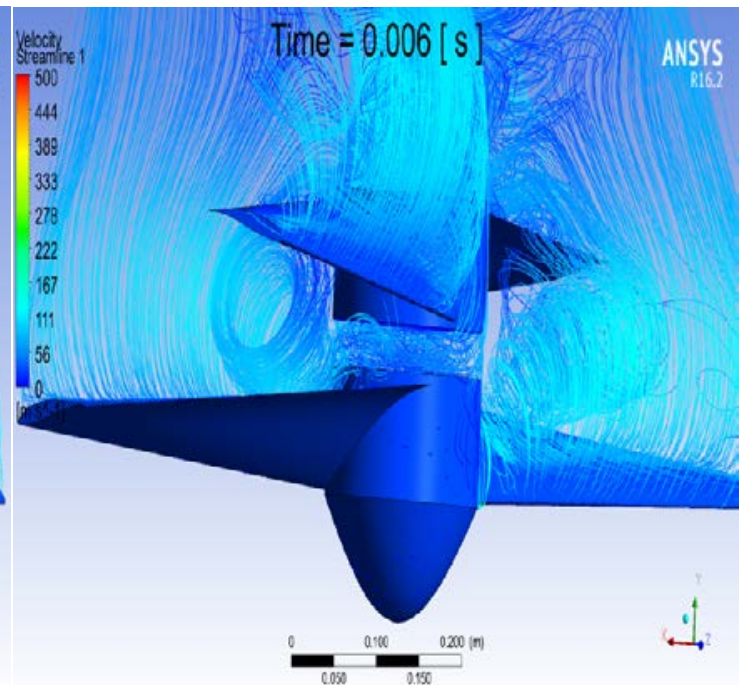

(b)

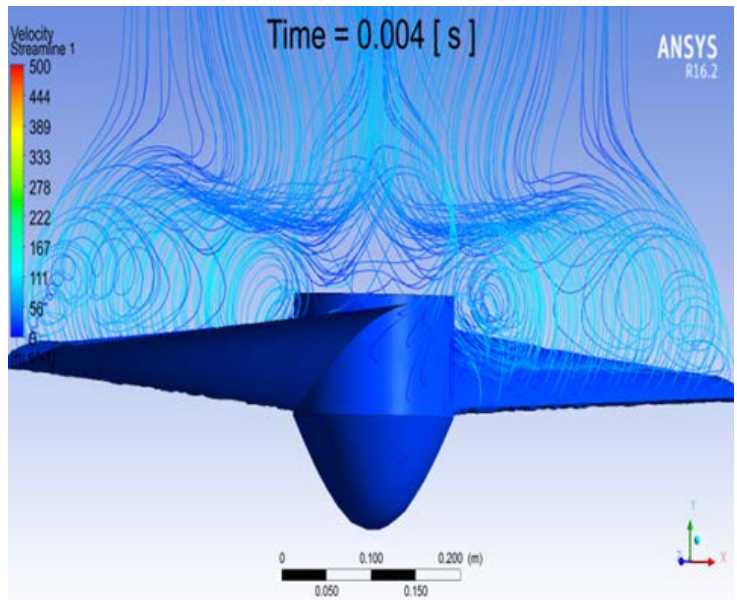

(c)

Figure 13. Velocity streamline (a) at time $0.004 \mathrm{~s}$ and at an axial distance of $14 \mathrm{~cm}$, and (b) at time $0.006 \mathrm{~s}$ and at an axial distance of $14 \mathrm{~cm}$; (c) single rotor. 


\subsubsection{SRRAT Performance at High Altitudes}

The specified magnitude at $10,000 \mathrm{~m}$ was set as the aircraft landing altitude, where the air density is equal to $0.4135 \mathrm{~kg} / \mathrm{m}^{3}$ (reduced around three times) and viscosity is equal to $1.458 \times 10^{-5} \mathrm{~kg} / \mathrm{ms}$. The maximum speeds were $5278 \mathrm{rpm}$ and $5234.743 \mathrm{rpm}$ at sea level and high altitude, respectively. Figure 14 shows that the time achieved to reach a steady-state for the single rotor at sea level was lower compared to the condition at high altitudes. The power output of the RAT at sea level was 62,361.307 W, as shown in Table 2, whereas the power output at a high altitude decreased to 20,653.069 W. Single rotors at sea level are hence attributed to higher performance as compared to single rotors operating at a high altitude. The total power that can be produced by RAT at sea level and high altitudes is $41507.184 \mathrm{~W}$. This proved that the following equation could be applied to the CRRAT system.

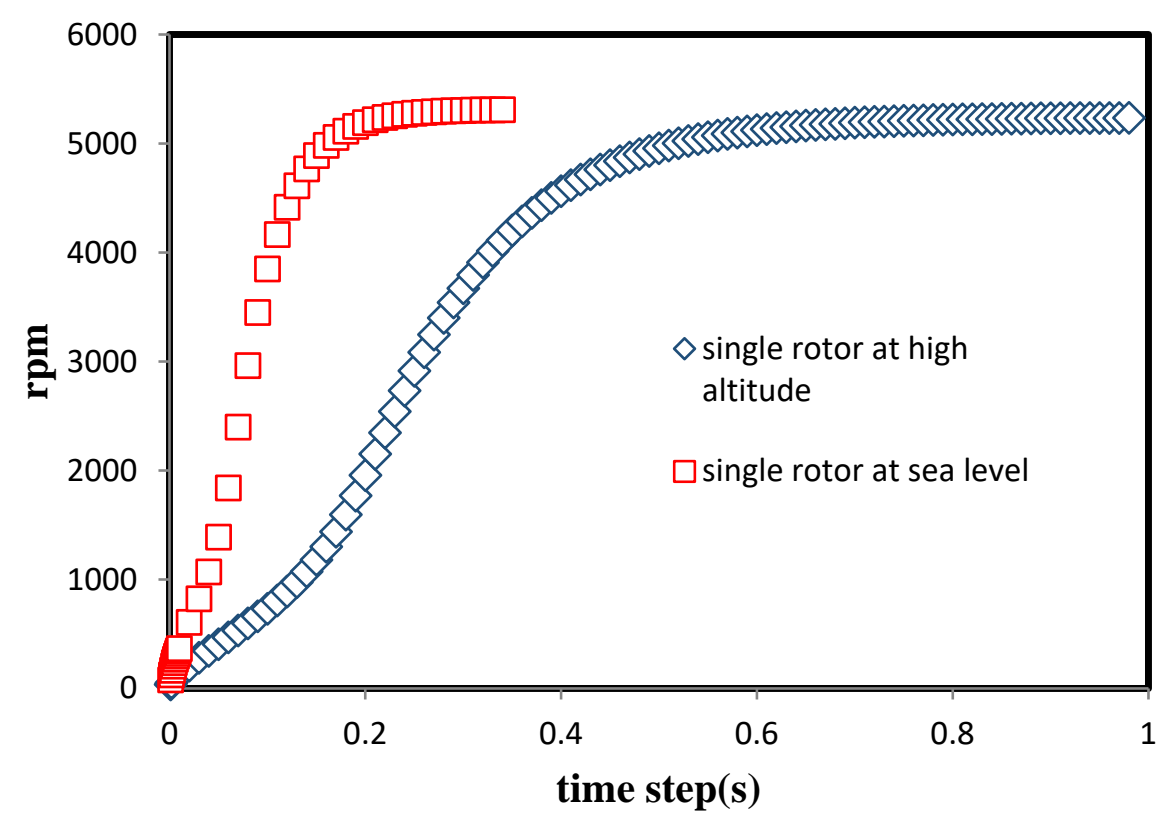

Figure 14. Relationship between rpm and time step.

Table 2. Power of rotor calculation.

\begin{tabular}{cccccccc}
\hline & RPM & Iyy & $\omega$ & Time & $\alpha$ & Torque & Power \\
\hline At sea level & 5278.4 & 0.0674 & 552.5 & 0.33 & 1674.2 & 112.9 & $62,361.3 \mathrm{~W}$ \\
\hline At high altitudes & 5234.7 & 0.0674 & 547.9 & 0.98 & 559.1 & 37.7 & $20,653.7 \mathrm{~W}$ \\
\hline
\end{tabular}

\section{Conclusions}

The present paper investigated the possibility of replacing the auxiliary power unit (APU) by improving the performance of a conventional ram air turbine (RAT) for power generation in aircrafts. The investigation focused on the counter-rotating technique to increase the performance of RAT by CFD analysis. The objectives were achieved successfully and concluding remarks are listed as follows:

(1) A comparative study of six airfoils has been performed by the 2-D CFD simulation method. The airfoil FX63-137-type showed a higher maximum lift-to-drag ratio at 110.725 as compared to the other airfoils. The aerodynamic characteristic of airfoil FX63-137 was validated at the same Reynolds number by the previous study and the result was in good agreement with experimental results.

(2) A three-dimension numerical simulation of a counter-rotating ram air turbine (CRRAT) was performed to select the optimum axial distance between the rotors. The optimum axial distance was calculated at $0.087 \mathrm{~d}(14 \mathrm{~cm})$, where the rotor performance 
increased by $13.72 \%$ and $9.04 \%$ compared with those at $0.062 \mathrm{~d}(10 \mathrm{~cm})$ and $0.106 \mathrm{~d}$ $(17 \mathrm{~cm})$, respectively.

(3) From the CFD analysis, the power produced by the single rotor was $62.36 \mathrm{~kW}$ (at sea level), whereas the counter-rotating rotor at an optimum axial distance was $113.26 \mathrm{~kW}$ (at sea level), and the performance of the RAT increased by almost $45 \%$ when the counter-rotating technique was used, as compared to the single-rotor ram air turbine. The counter-rotating system efficiency increased due to the addition of the second rotor (rear rotor) and also due to the simultaneous operation of the two rotors.

Author Contributions: M.M.M.S. was responsible for designing the models, running the simulation, and obtaining the results. M.F.Z. and N.A.S. wrote the paper. D.H.D. was responsible for analyzing the data and for the validation. S.M. reviewed and edited the work, was responsible for acquiring funding, and was the main supervisor of the project. All authors have read and agreed to the published version of the manuscript.

Funding: This research study was funded by Universiti Tun Hussein Onn Malaysia, grant number $\mathrm{H} 772$, and the APC was also funded by H772.

Institutional Review Board Statement: Not applicable.

Informed Consent Statement: Not applicable.

Data Availability Statement: Exclude this statement.

Acknowledgments: The authors acknowledge the technical support provided by the Computational Fluid Dynamics (CFD) laboratory at the Faculty of Mechanical and Manufacturing Engineering, Universiti Tun Hussein Onn, Malaysia.

Conflicts of Interest: The authors declare no conflict of interest. The funders had no role in the design of the study; in the collection, analyses, or interpretation of data; in the writing of the manuscript, or in the decision to publish the results.

\section{Nomenclature}

$\begin{array}{ll}\text { Acronyms } & \\ \text { APU } & \text { auxiliary power unit } \\ \text { CFD } & \text { computational fluid dynamics } \\ \text { CRRAT } & \text { counter-rotating ram air turbine } \\ \text { MRF } & \text { Moving Reference Frame } \\ \text { SRRAT } & \text { single-rotor ram air turbine } \\ \text { SST } & \text { shear stress transport } \\ \text { UDF } & \text { user-defined function } \\ \text { Greek Letters } & \\ \alpha & \text { angle of attack (degree) } \\ \varepsilon & \text { turbulence dissipation rate }\left(\mathrm{m}^{2} \mathrm{~s}^{-3}\right) \\ \tau & \text { shear stress }\left(\mathrm{N} / \mathrm{m}^{2}\right) \\ \mu & \text { fluid viscosity }(\mathrm{kg} /(\mathrm{s} . \mathrm{m})) \\ \mathrm{v} & \mathrm{kinematic} \text { viscosity }\left(\mathrm{m}^{2} / \mathrm{s}\right) \\ \omega & \text { turbulence dissipation rate }\left(\mathrm{s}^{-1}\right) \\ \mu & \text { fluid viscosity }(\mathrm{kg} /(\mathrm{s} . \mathrm{m})) \\ \text { Latin Letters } & \\ \text { Cd } & \mathrm{Cd} \\ \mathrm{Cl} & \mathrm{Cl} \\ \mathrm{g} & \mathrm{g} \\ \mathrm{k} & \mathrm{k} \\ \mathrm{R} & \mathrm{R} \\ \mathrm{U} & \mathrm{U} \\ & \end{array}$




\section{References}

1. Schipper, L. Energy Conservation and the Environment: Conflict or Complement? 1978. Available online: https://www.osti.gov / servlets/purl/6239110 (accessed on 7 June 2021).

2. Hu, S.; Fruin, S.; Kozawa, K.; Mara, S.; Winer, A.M.; Paulson, S.E. Aircraft emission impacts in a neighborhood adjacent to a general aviation airport in Southern California. Environ. Sci. Technol. 2009, 43, 8039-8045. [CrossRef] [PubMed]

3. Unique (Flughafen Zürich AG), P.O.; Box, CH-8058 Zurich. Fixed Energy Systems for Aircraft at Zurich Airport. Environmental Services and Technical Facility Management [environment@unique.ch]. 2009. Available online: http:/ /www.unique.ch; http: //www.obsa.org/Lists/.../353/Fixed_energy_systems_aircraft_Zurich_AirportEN.pdf (accessed on 9 July 2021).

4. Yuan, W. Second-Generation High-Temperature Superconducting Coils and Their Applications for Energy Storage; Springer Science \& Business Media: Berlin, Germany, 2011.

5. Aircraft Ground Energy System Ages. IST-Edelstahl-Anlagenbau AG. Schorenstrasse 54 CH 3645 Thun-Gwatt, Switzerland. 2014. Available online: https:/ / www.airport-suppliers.com/supplier/ist-edelstahl-anlagenbau-ag/ (accessed on 17 August 2021).

6. Cramoisi, G. Air Crash Investigations: Running Out of Fuel, How Air Transat 236 Managed to Fly 100 Miles without Fuel and Land Safely; Lulu.com: Morrisville, CA, USA, 2010.

7. Weimerskirch, H.; Martin, J.; Clerquin, Y.; Alexandre, P.; Jiraskova, S. Energy saving in flight formation. Nature 2001, $413,697$. [CrossRef] [PubMed]

8. Zolidis, M.J. Emergency airplane RATs. Present. IEEE Rock River Val. Sect. 2006, 6, 1-35.

9. Kumar, P.S.; Bensingh, R.J.; Abraham, A. Computational analysis of $30 \mathrm{~kW}$ contra rotor wind turbine. ISRN Renew. Energy 2012, 2012, 939878. [CrossRef]

10. Wei, X.; Huang, B.; Liu, P.; Kanemoto, T.; Wang, L. Experimental investigation into the effects of blade pitch angle and axial distance on the performance of a counter-rotating tidal turbine. Ocean. Eng. 2015, 110, 78-88. [CrossRef]

11. Lee, S.; Kim, H.; Lee, S. Analysis of aerodynamic characteristics on a counter-rotating wind turbine. Curr. Appl. Phys. 2010, 10, S339-S342. [CrossRef]

12. Kumar, P.S.; Abraham, A.; Bensingh, R.J.; Ilangovan, S. Computational and Experimental Analysis of a Counter-Rotating Wind Turbine System; NISCAIR-CSIR: New Delhi, India, 2013.

13. Lee, S.; Son, E.; Lee, S. Velocity interference in the rear rotor of a counter-rotating wind turbine. Renew. Energy 2013, 54, 235-240. [CrossRef]

14. Pereira, J.C.F.; da Silva Chaves Fernandes Pereira, J.M.; Ferreira, R.M.C. Computational Simulation in a Counter-Rotating Horizontal Axis Turbine; LASEF, Mechanical Engineering Department, Instituto Superior Técnico/Technical University of Lisbon: Lisbon, Portugal, 2009.

15. Jung, S.N.; No, T.S.; Ryu, K.W. Aerodynamic performance prediction of a $30 \mathrm{~kW}$ counter-rotating wind turbine system. Renew. Energy 2005, 30, 631-644. [CrossRef]

16. Didane, D.H.; Rosly, N.; Zulkafli, M.F.; Shamsudin, S.S. Performance evaluation of a novel vertical axis wind turbine with coaxial contra-rotating concept. Renew. Energy 2018, 115, 353-361. [CrossRef]

17. Didane, D.H.; Rosly, N.; Zulkafli, M.F.; Shamsudin, S.S. Numerical investigation of a novel contra-rotating vertical axis wind turbine. Sustain. Energy Technol. Assess. 2019, 31, 43-53. [CrossRef]

18. Didane, D.H.; Maksud, S.M.; Zulkafli, M.F.; Rosly, N.; Shamsudin, S.S.; Khalid, A. Performance investigation of a small Savonius-Darrius counter-rotating vertical-axis wind turbine. Int. J. Energy Res. 2020, 44, 9309-9316. [CrossRef]

19. Didane, D.H.; Maksud, S.M.; Zulkafli, M.F.; Rosly, N.; Shamsudin, S.S.; Khalid, A. Experimental Study on the Performance of a Savonius-Darrius Counter-Rotating Vertical Axis Wind Turbine. In IOP Conference Series: Earth and Environmental Science; IOP Publishing: Bristol, UK, 2019; Volume 268, p. 012060.

20. Moir, I.; Seabridge, A. Design and Development of Aircraft Systems; John Wiley \& Sons: Hoboken, NJ, USA, $2012 ;$ Volume 68.

21. Ragheb, M.; Ragheb, A.M. Wind turbines theory-the betz equation and optimal rotor tip speed ratio. In Fundamental and Advanced Topics in Wind Power; InTech: Rijeka, Croatia, 2011.

22. Jamdade, P.G.; Patil, S.V.; Jamdade, S.G. Assessment of Power Coefficient of an Offline Wind Turbine Generator System. Electron. J. Energy Environ. 2013, 1, 41-48. [CrossRef]

23. Gao, X.; Hu, J. Numerical simulation to the effect of rotation on blade boundary layer of horizontal axial wind turbine. In Proceedings of the World Non-Grid-Connected Wind Power and Energy Conference (WNWEC), Nanjing, China, 5-7 November 2010; pp. 1-4.

24. Drumheller, D.P.; D'Antonio, G.C.; Chapman, B.A.; Allison, C.P.; Pierrakos, O. Design of a micro-wind turbine for implementation in low wind speed environments. In Proceedings of the Systems and Information Engineering Design Symposium (SIEDS), Charlottesville, VA, USA, 24-24 April 2015; pp. 125-130.

25. Zhang, C.; Hu, J. The UAE wind turbine performance prediction using wind tunnel airfoil data. In Proceedings of the World Non-Grid-Connected Wind Power and Energy Conference (WNWEC), Nanjing, China, 5-7 November 2010; pp. 1-5.

26. Chaudhary, U.; Nayak, S.K. Micro and small-scale HAWT blades airfoils study through CFD for low wind applications. In Proceedings of the India Conference (INDICON), 2015 Annual IEEE, New Delhi, India, 17-20 December 2015; pp. 1-6.

27. Percis, E.S.; Ramesh, L.; Nalini, A. In Proceedings of the Investigation of Harnessing High Altitude Tethered Rotorcraft Wind Systems. Tiruchengode, India, 27-29 December 2012. 
28. Kaminsky, C.; Mokhtar, W. A CFD Study of Wind Turbine Aerodynamics. In Proceedings of the 2012 ASEE North Central Section Conference, Toledo, OH, USA, 24 March 2012.

29. Ceyhan, O. Towards 20MW wind turbine: High Reynolds number effects on rotor design. In Proceedings of the 50th AIAA Aerospace Sciences Meeting including the New Horizons Forum and Aerospace Exposition, Nashville, TN, USA; $2012 ;$ p. 1157.

30. Lee, N.J.; Kim, I.C.; Kim, C.G.; Hyun, B.S.; Lee, Y.H. Performance study on a counter-rotating tidal current turbine by CFD and model experimentation. Renew. Energy 2015, 79, 122-126. [CrossRef]

31. Park, S.; Park, S.; Rhee, S.H. Influence of blade deformation and yawed inflow on performance of a horizontal axis tidal stream turbine. Renew. Energy 2016, 92, 321-332. [CrossRef]

32. Digraskar, D.A. Simulations of Flow Over Wind Turbine. Master's Theses, University of Massachusetts Amherst, Amherst, MA, USA, 2010; pp. 1-84.

33. Manwell, J.F.; McGowan, J.G.; Rogers, A.L. Wind Energy Explained: Theory, Design and Application; John Wiley \& Sons: Hoboken, NJ, USA, 2010.

34. Sun, Y.; Zhang, L. Numerical simulation of the unsteady flow and power of horizontal axis wind turbine using sliding mesh. In Proceedings of the Power and Energy Engineering Conference (APPEEC), 2010 Asia-Pacific, Chengdu, China, 28-31 March 2010; pp. 1-3.

35. Qiu, M.; Zhou, Z.; Zhang, J. Three-dimensional flow simulation for horizontal axis wind turbine. In Proceedings of the World Non-Grid-Connected Wind Power and Energy Conference (WNWEC), Nanjing, China, 24-26 September 2009; pp. 1-4.

36. Hartwanger, D.; Horvat, A. 3D modelling of a wind turbine using CFD. In Proceedings of the NAFEMS Conference, The New Forest, UK, 18 June 2008.

37. Kanyako, F.; Janajreh, I. Investigating blade performance of small horizontal axis wind turbine based on blade element momentum theory. In Proceedings of the Applications of Information Technology to Renewable Energy Processes and Systems (IT-DREPS), 2013 1st International Conference \& Exhibition, Amman, Jordan, 29-31 May 2013; pp. 85-90. 